\title{
Original Research Article Novel Nano-Sized Iron Complex Application Using Folate Based Imaging Agent
}

\author{
Saeed Akbarian ${ }^{1}$, Asma Keshavarz ${ }^{2}$, Esmaeel Mohammadi Pargoo ${ }^{3}$, Nasser Nassiri Koopaei ${ }^{4}$, \\ Hamid Moloudian ${ }^{5}$, Mostafa Saffari ${ }^{2}$, Hadi Hejazinia ${ }^{4}$, Masood Bamedi ${ }^{6}$, Mehdi Shafiee Ardestani ${ }^{1}$ \\ ${ }^{1}$ Department of Radiopharmacy, Faculty of Pharmacy, Tehran University of Medical Sciences, Tehran, Iran \\ ${ }^{2}$ Pharmaceutical Branches, Islamic Azad University, Tehran, Iran \\ ${ }^{3}$ Department of Pharmaceutical Biotechnology, Faculty of Pharmacy, Tehran University of Medical Sciences, Tehran, Iran \\ ${ }^{4}$ Pharmaceutical Quality Assurance Research Center, Tehran University of Medical Sciences, Tehran, Iran \\ ${ }^{5}$ Department of Biology, Science and Research Branch, Islamic Azad University, Tehran, Iran \\ ${ }^{6}$ Depertment of Periodontology and Oral and Dental Disease Research Center, Zahedan University of Medical Science, Zahedan, Iran
}

Email address:

shafieeardestani@tums.ac.ir (M. S. Ardestani), shafieeardestani@gmail.com (M. S. Ardestani)

\section{To cite this article:}

Saeed Akbarian, Asma Keshavarz, Esmaeel Mohammadi Pargoo, Nasser Nassiri Koopaei, Hamid Moloudian, Mostafa Saffari, Hadi Hejazinia, Masood Bamedi, Mehdi Shafiee Ardestani. Original Research Article Novel Nano-sized Iron Complex Application Using Folate Based Imaging Agent. American Journal of Nanosciences. Vol. 3, No. 1, 2017, pp. 9-18. doi: 10.11648/j.ajn.20170301.12

Received: December 23, 2016; Accepted: January 6, 2017; Published: March 30, 2017

\begin{abstract}
Design and evaluation of new chemically nano composites towards molecular imaging of malignant tumors is being considered as a kind of medical global research interests. In the current experiment novel nano-composite based on gadolinium ions and anionic linear globular Dendrimer G2 (as biocompatible biodegradable hybrid nanomaterial grafted to folic acid was developed and biophysically assayed. The results showed a very good Magnetic Resonance (MR) relaxivity data on T2 decreasing as well as a very good cellular uptake and tolerance. The complex was found toxic with employing apoptosis as main mechanism of action on cancerous cells respectively. Based on results it could be concluded that such nano-complex may be used as novel theranostic agent in further in vivo practices in near future.
\end{abstract}

Keywords: Folic Acid, Gadolinium, Anionic Linear Globular Dendrimer G2, Magnetic Resonance

\section{Introduction}

In current medicinal practice attractive reverberation imaging (MRI) system has an across the board application in diagnosis [1]. It is noninvasive and gives high spatial resolution [2]. Unwinding time as the major figure differentiation of MRI pictures is routinely improved by means of exogenous complexity specialists other than the endogenous varieties. Among the complexity specialists in clinical practice chelated paramagnetic salts of gadolinium (Gd) and super paramagnetic iron oxide nanoparticles (SPIONPs) are outstanding [1]. SPIONPs have been utilized as colloidal go between for attractive hyperthermia of malignancies [3].

SPIONPs need changeless polarization and in this manner conglomeration issue minimizes [2]. Their super paramagnetic nature renders them the ability to be used in low focuses in vivo [4]. As opposed to gadolinium salts, Iron Based nanoparticle act free of the fringe water environment and decrease the powerful transverse unwinding time (T2) of tissues with a superior lethality profile $[5,6]$.

Additionally, polarization of Iron Based nanoparticle vanishes when they do not have an outside attractive field. These nanoparticles (NPs) additionally indicate amazing saturation magnetization [2]. Clinical viability and antagonistic medication responses of complexity operators can be enhances by focused delivery $[5,7]$. Then again, focusing on the particular tissue enhances their clinical materialness. Such point is achievable through different instruments. One of the detached focusing on courses is to utilize the broad vascularization and perfusion of the threatening tissue giving upgraded pervasion and maintenance (EPR) impact. By the by, various downsides confine the utility of such approach like non-specificity, contingent upon expansive number of parameters and ease of 
use in strong tumors. Another approach is to focus on the overexpressed high-partiality receptors on the malignant cells that commonly intervene endocytosis and gives a transportation road through the cell membrane [7]. Use of supplements, for example, folic corrosive (FA) could be viewed as the decision as they are routinely disguised for high mitotic action and consequently exchanging the imaging attachments [8]. FA is worthwhile over other focusing on specialists like transferrin, counter acting agent, peptides and hormones for absence of immunogenicity, use in DNA union and little atomic size $[4,9]$.

Amid the late years amazing exploration has been centered around dendrimer chemistry\{starting by namazi et al to Ardestani et al, 2016 \#3-7\} and demonstrated that negatively charged dendrimers could be used as a stage to explicitly target harmful cells when connected to predefined focusing on atoms and convey differentiate specialists and medications. The dendrimer goes about as a stage exchange specialist from natural to watery media and attractive NPs stabilizer $[3,4,7,8,10]$. In this research, we have developed anionic G2 PEGylated based dendrimers conjugated with FA. The dendrimer composed of poly ethylene glycol core with citric acid branches that facilitates insertion of functionalities. The structure provides versatile surface chemistry and high binding capacity. FA moieties target the tissue through multiple binding sites on the dendrimer and the cell surface. Studies showed remarkable structural stability. FT-IR, AFM and size and charge tests were done to verify the proper conjugation of Iron Based nanoparticle and FA.

\section{Material and Methods}

\subsection{Synthesis of Dendrimers $G_{1}$ and $G_{2}$}

Combination of dendrimers G1 and G2was performed by already created strategy $[11,12]$, however quickly, compound G1dendrimer was synthesized with the response of PEG 600 and DCC in anhydrous DMSO. At that point, by evacuating the DCC and including citrus extract, the arrangement shading transformed into orange with stench. Yellow-browndendrimer product was gotten after water expansion and last filtration. Then, G1dendrimer was filtered by dialysismembrane (500-1000 Da pore measure) with 1600 overlay volume and a large portion of the dialysis sack concentration. The dendrimer was lyophilized in more than $90 \%$ yield. G2dendrimersynthesizedwith addition of DCC and citrus extract to the solution of G1dendrimer in DMSO until a tick dim cream solution developed. The response was ended as the previous one and the item was purified. G2dendrimerstructure ( $\geq 70 \%$ yield) was confirmed by FTIR. Zetasizer (dynamic light dispersing, DLS) gave size and electric charge of G1 and G2dendrimers.

\subsection{Dendrimer Conjugation with FA}

The $\mathrm{G}_{2}$ dendrimers used in this study were modified through reaction with DCC to activate the carboxyl functionality on citric acid moieties. Then equimolar FA was added and the mixture was stirred for $72 \mathrm{~h}$. The purification and lyophilization process were also performed to provide the FA-Dendrimer conjugate. FT-IR and HNMR spectroscopy were used to verify the conjugate structure.

\subsection{Preparation of Iron Based Nanoprobe}

Iron containing nanoprobe were prepared through the method of controlled chemical co-precipitation of $\mathrm{Fe}^{2+}$ and $\mathrm{Fe}^{3+}$ ions. Briefly, fifty milliliters of $1.0 \mathrm{M} \mathrm{Fe}^{2+}$ and $2.0 \mathrm{M}$ $\mathrm{Fe}^{3+}$ solutions were prepared with deionized water in two beakers, and then transferred to a $250 \mathrm{~mL}$ three necked flask together. When the solution was heated to $80^{\circ} \mathrm{C}, \mathrm{NH}_{4} \mathrm{OH}(25$ $\mathrm{wt} \%$ ) was added drop wise under argon protection and vigorous mechanical stirring $(700-800 \mathrm{rpm})$ until $\mathrm{pH}=10$ 11. As the base was added, the solution immediately turned black indicating the formation of iron oxide in the system. The solution was heated and refluxed at $80^{\circ} \mathrm{C}$ for $1 \mathrm{~h}$, and then the precipitated powders were collected by magnetic separation. The obtained magnetic NPs were washed immediately with deionized water for five times and then with dichloromethane for three times. The final product was dried into powder at $40^{\circ} \mathrm{C}$ under vacuum [6].

\subsection{Iron Complex Formation onto the Dendrimer Conjugate}

$10 \mathrm{mg}$ portion of $\mathrm{G}_{2}$ dendrimer-FA conjugate was dissolved in $6 \mathrm{~mL}$ of distilled water. The solution was stirred thoroughly and then placed under $\mathrm{N}_{2}$ flow. Then equimolar concentration of Iron containing nanoprobe was added drop wise at room temperature. The reaction mixture was stirred for $12 \mathrm{~h}$. After the reaction mixture turned into pale brown, the supernatant was decanted while a magnet retained iron oxide loaded NPs. The loaded dendrimer conjugate structure and stability was assessed using FT-IR, size and charge determination (Zetasizer), atomic force microscopy (AFM) and UV spectroscopy.

\subsection{Cell Culture and Toxicity Assessments}

Human chest tumor MCF-7 cell line and run of the mill cells were gotten from Pasteur Institute of Iran and kept up at $37^{\circ} \mathrm{C}$ and $5 \% \mathrm{CO}_{2}$ in DMEM medium supplemented with $10 \%$ fetal dairy animals like serum (FBS), $1 \%$ penicillin/streptomycin and L-glutamine (1\%).100 $\mu \mathrm{LMCF}$ 7 cell test was added to a flask containing $7 \mathrm{ml}$ of culture medium and shaken well. The measure was performed to assess cell augmentation, sensibility, and cytotoxicity of the distinction pro. In this test, 10000 cells were moved into 96-well plates separated into $4 \times 24$ social events with duplicates. Adjust administrator with 5, 10, 50 and 100 $\mu \mathrm{g} / \mathrm{mL}$ was added to the wells and DMSO and dendrimer were the controls. The plates were brought forth for $24 \mathrm{~h}$ at $37^{\circ} \mathrm{C}$ and $5 \% \mathrm{CO}_{2}$. XTT stamping $(5 \mathrm{~mL})$ and Electroncoupling $(0.1 \mathrm{~mL})$ reagents were mixed and $50 \mu \mathrm{L}$ of the game plan was to each well. The wells were brought forth for $4 \mathrm{~h}$ in cloudiness at $37^{\circ} \mathrm{C}$ and $5 \% \mathrm{CO}_{2}$. The ELISA 
peruser contraption (Biohit, BP800) was used to assess the OD450.

To focus the concentrating on capacities of the dendrimer-secured alluring nanoparticles, MCF-7 cells were seeded in well plates with $250 \mu \mathrm{L}$ of media and allowed to form into a monolayer over a 48 -h period. The media were suctioned and supplanted by $100 \mu \mathrm{L}$ media with dendrimer-secured nanoparticles centralizations of $0.1,0.25$, $0.5,0.75$ and $1 \mathrm{M}$ in autonomous wells for 24-h agonizing; water, cells without the many-sided quality master and $1 \mathrm{M}$ sans nanoparticles dendrimer served as the control. The cells were restricted from the wells with enzymatic process. The occurring suspensions were then centrifuged for $10 \mathrm{~min}$ at $1500 \mathrm{rpm}$ to casing cell pellets. After aspirating the supernatants, $500 \mu \mathrm{L}$ new PBS was incorporated to each tube and the tubes were incited to shape suspensions before repeating centrifugation. A 2\% supported paraformaldehyde solution was added to each pellet to settle the cells. Aspiration, PBS washing, and centrifugation were performed twice before in the end suspending the settled cells in500 $\mu \mathrm{L}$ immaculate PBS. IC50 and EC50 were overviewed for the separation administrator.

\subsection{MR in Vitro Assay}

MR imaging was performed with a 3 Tesla MRI contraption in Rajaee Hospital, Tehran. The consequent pictures were used to choose the best centralization of the separation pro. T1 and T2 loosening up times were figured for the imaging. Dicomwork (interpretation 1.3.0.5),

\section{Results}

Microdicom (variation 0.7.1.1824), Matlab (1.0.0.1) and Microsoft office Excel 2007 were used as a part of the figuring.

\subsection{Size and Charge Determination}

Size and electric charge of G1 and G2dendrimers was determined by zetasizer (dynamic light scattering, DLS).

\subsection{FT-IR Spectroscopy}

FT-IR spectroscopy was used to verify the structure of the synthesized dendrimer and the main peaks were investigated. $\mathrm{KBr}$ tablets were prepared for the analysis.

\subsection{Atomic Force Microscopy}

AFM or scanning force microscopy (SFM) as a type of scanning probe microscopy (SPM) provides resolution on the order nanometer scale. The nano-conjugated dendrimer was covered on the surface of mica crystals and used for contact mode of AFM. Two and three dimensional microscopy of the dendrimer was prepared before and after conjugation with Iron.

\subsection{UV Spectroscopy}

Scanning UV spectroscopy was used to investigate the proper conjugation of the iron nanoparticles with the dendrimer structure. The UV scan was performed before and after the conjugation procedure.

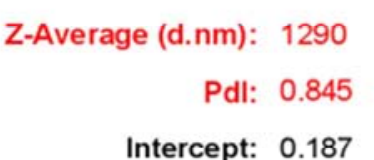

Intercept: 0.187

$\begin{array}{ll} & \text { Diam. }(\mathrm{nm}) \\ \text { Peak 1: } & 361 \\ \text { Peak 2: } & 5220 \\ \text { Peak 3: } & 0.00\end{array}$

Size Distribution by Number

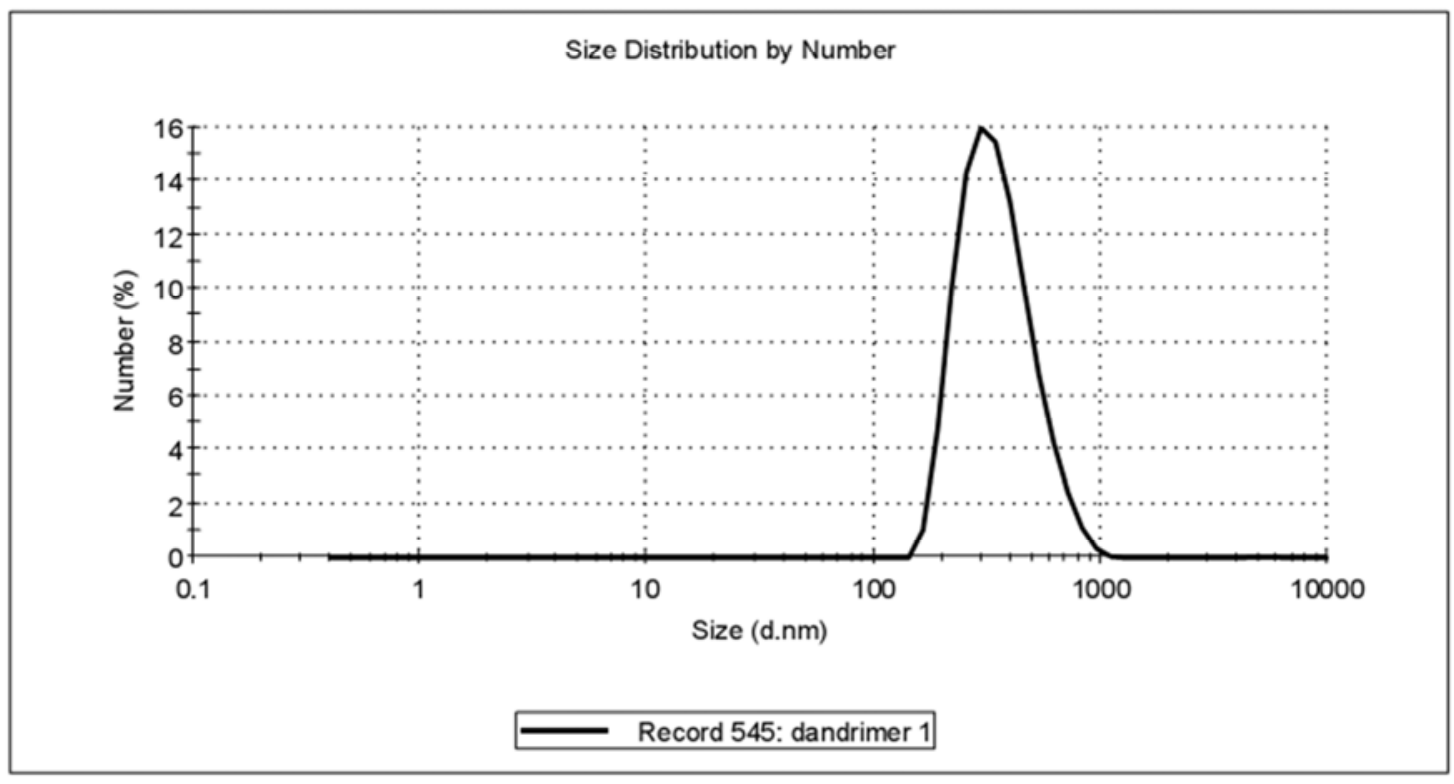

Record 545: dandrimer 1

$\begin{array}{ll}\text { \% Number } & \text { Width }(\mathrm{nm}) \\ 99.9 & 138 \\ 0.1 & 729 \\ 0.0 & 0.00\end{array}$

$0.0-0.00$ 
Results

$\begin{array}{rlllll} & & \text { Diam. }(\mathrm{nm}) & \% \text { Intensity } & \text { Width }(\mathrm{nm}) \\ \text { Z-Average (d.nm): } 5530 & \text { Peak 1: } & 595 & 100.0 & 35.9 \\ \text { Pdl: } 1.000 & \text { Peak 2: } & 0.00 & 0.0 & 0.00 \\ \text { Intercept: } & 0.739 & \text { Peak 3: } & 0.00 & 0.0 & 0.00\end{array}$

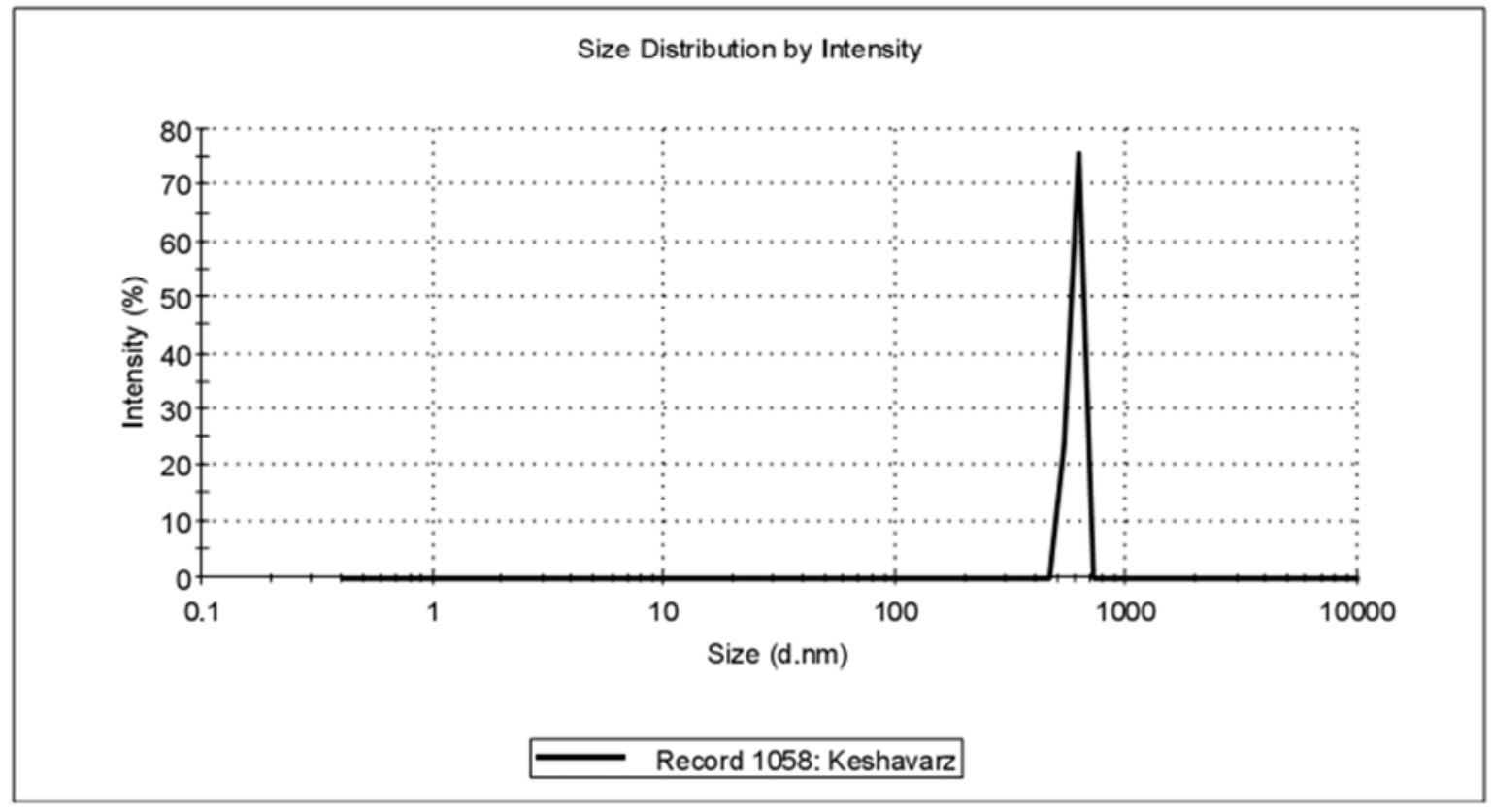

(B)

Figure 1. Depiction of results regarding size distribution pattern of dendrimer-folate conjugate (A) and iron-dendrimer-folate (B).

\section{Results and Discussion}

\subsection{NP Synthesis, Surface Modification and Magnetic Properties}

Gel chromatography was performed to ensure the synthesis and purity of the synthesized contrast agent. The gel chromatography of the sample was run and the G2 dendrimer with higher molecular weight emerged first rather than the citric acid with lower molecular weight. Then TLC showed that a distinct bond has been added in comparison to the previous sample that confirmed the synthesis.

$1318 \mathrm{~cm}^{-1}$ peak in FT-IR relates to the terminal G1 citric acid moiety and the new citric acids ester $\mathrm{C}-\mathrm{O}$ bond that verifies the synthesis of the $\mathrm{G} 2$ dendrimer. $1647 \mathrm{~cm}^{-1}$ peak stands for the terminal G2 citric acid moieties. The wide peak $2500-3430 \mathrm{~cm}^{-1}$ confirms the presence of the terminal citric acid carboxyl group.

The figure 1 showed the FA-Dendrimer conjugate diameter of $361 \mathrm{~nm}$ before SPIONP loading that lies in the nanometer range and its diameter after SPIONP loading that has increased to $595 \mathrm{~nm}$. The retention of the size in the nanometer range after iron loading confirmed the proper synthesis and no significant morphology or magnetism change of the final iron loaded FA-Dendrimer conjugate.

Figure 2 shows the results of charge determination the FADendrimer conjugate. The FA-Dendrimer conjugate has a $11.1 \mathrm{mV}$ charge. Figure 4 relates to the SPIONP loaded FADendrimer conjugate with a positive $7.44 \mathrm{mV}$ charge. The surface charge inversion confirms the loading of the iron on the surface of the FA-Dendrimer conjugate. Zeta potential study results show that the negative charge of the contrast agent due to FA prevents the adsorption of the agent to the cells and does not cause cytotoxicity. UV spectroscopic study of FA-Dendrimer conjugate before and after SPIONP loading showed that a new peak at $280 \mathrm{~nm}$ was present after SPIONP loading. This peak verifies the proper loading of the SPIONP on the FA-Dendrimer conjugate surface.

The figures 3 and 4 show the two dimensional AFM study of FA-Dendrimer conjugate before and after iron complex formation.

The AFM studies demonstrate that the sizes of the SPIONP loaded FA-Dendrimer conjugate remained unchanged in comparison with that of the FA-Dendrimer conjugate. On the other hand it was observed that the particles did not aggregate together into fusion bodies, implying reserved magnetic properties. 
Results

$\begin{array}{clllll} & & \text { Mean }(\mathrm{mV}) & \text { Area }(\%) & \text { Width }(\mathrm{mV}) \\ \text { Zeta Potential }(\mathrm{mV}): & -11.1 & \text { Peak 1: } & -14.0 & 89.9 & 6.27 \\ \text { Zeta Deviation }(\mathrm{mV}): & 8.46 & \text { Peak 2: } & 4.28 & 10.1 & 1.62 \\ \text { Conductivity }(\mathrm{mS} / \mathrm{cm}): & 0.0520 & \text { Peak 3: } & 0.00 & 0.0 & 0.00\end{array}$

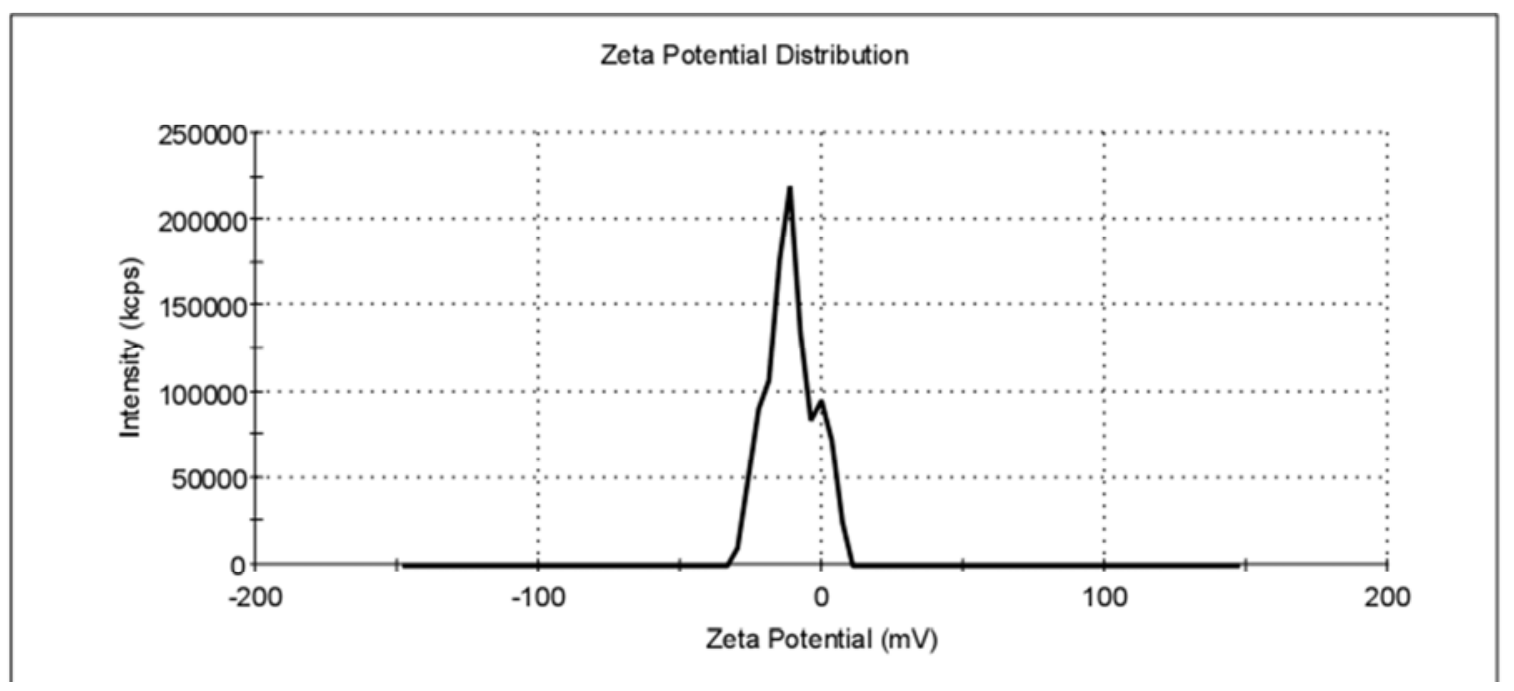

(A)

Results

Zeta Deviation $(\mathrm{mV}): 13.6$

Conductivity $(\mathrm{mS} / \mathrm{cm}): 1.64$

$\begin{array}{llll} & \text { Mean }(\mathrm{mV}) & \text { Area }(\%) & \text { Width }(\mathrm{mV}) \\ \text { Peak 1: } & 7.44 & 100.0 & 13.6 \\ \text { Peak 2: } & 0.00 & 0.0 & 0.00 \\ \text { Peak 3: } & 0.00 & 0.0 & 0.00\end{array}$

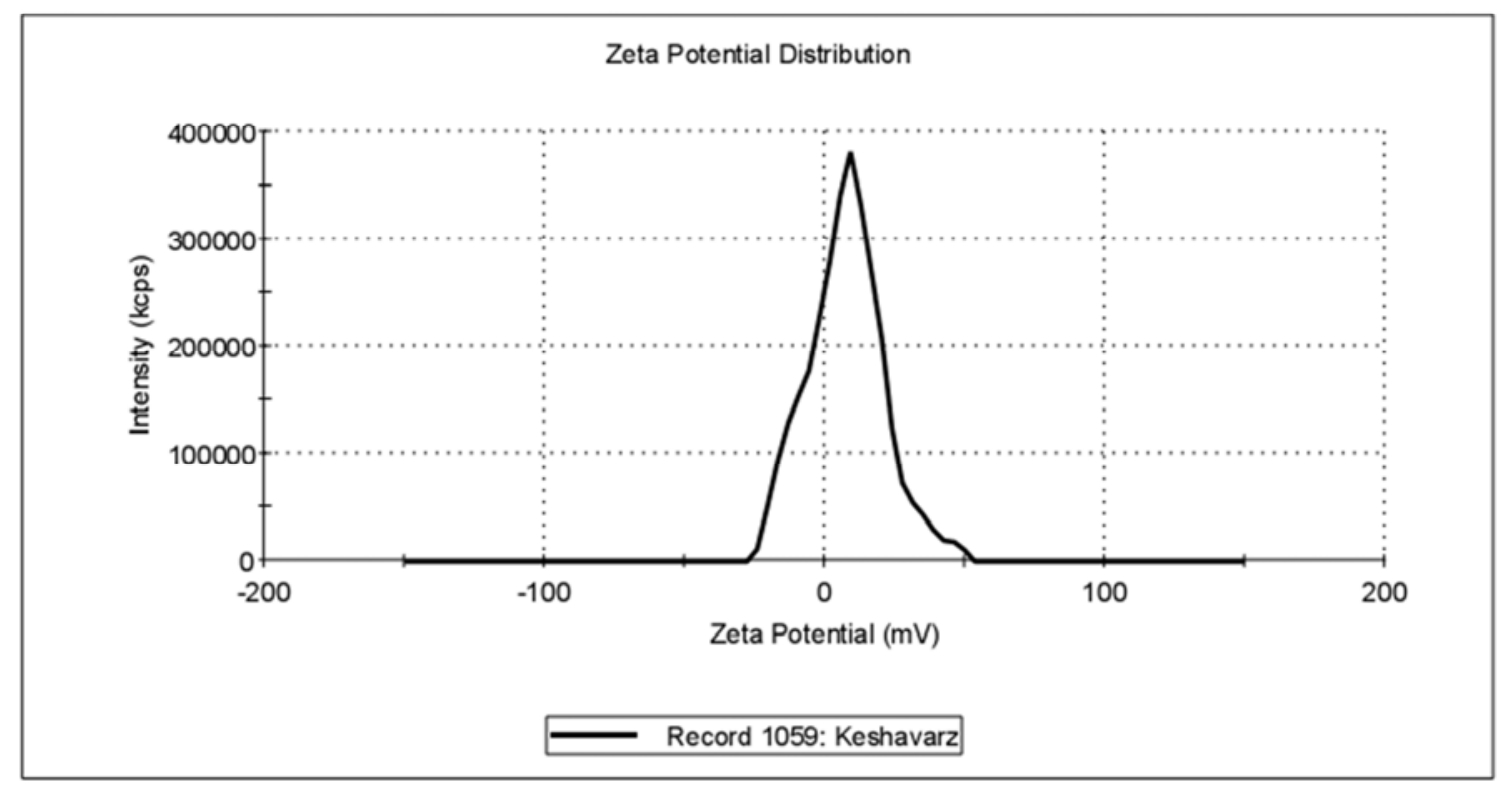

(B)

Figure 2. Depiction of results regarding zeta-potential of dendrimer-folate conjugate (A) and iron-dendrimer-folate (B). 


\section{$(3,108)$ x: $0.0586 \mu \mathrm{m}$ y: $2.109 \mu \mathrm{m}$ z: $0.009848 \mu \mathrm{m}$}

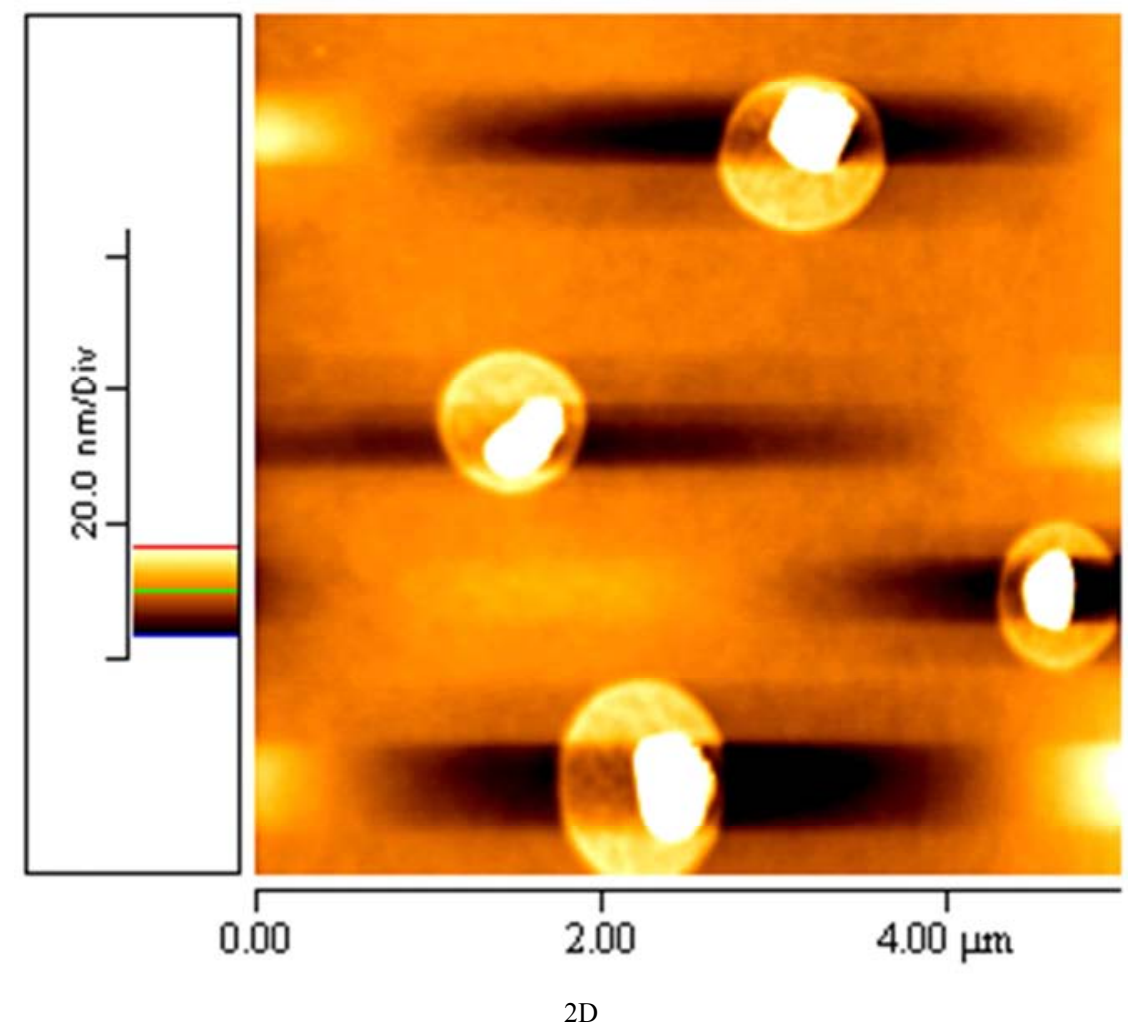

$(2,213) \mathrm{x}: 0.0391 \mu \mathrm{m} \quad \mathrm{y}: 4.160 \mu \mathrm{m}$ z: $0.01535 \mu \mathrm{m}$

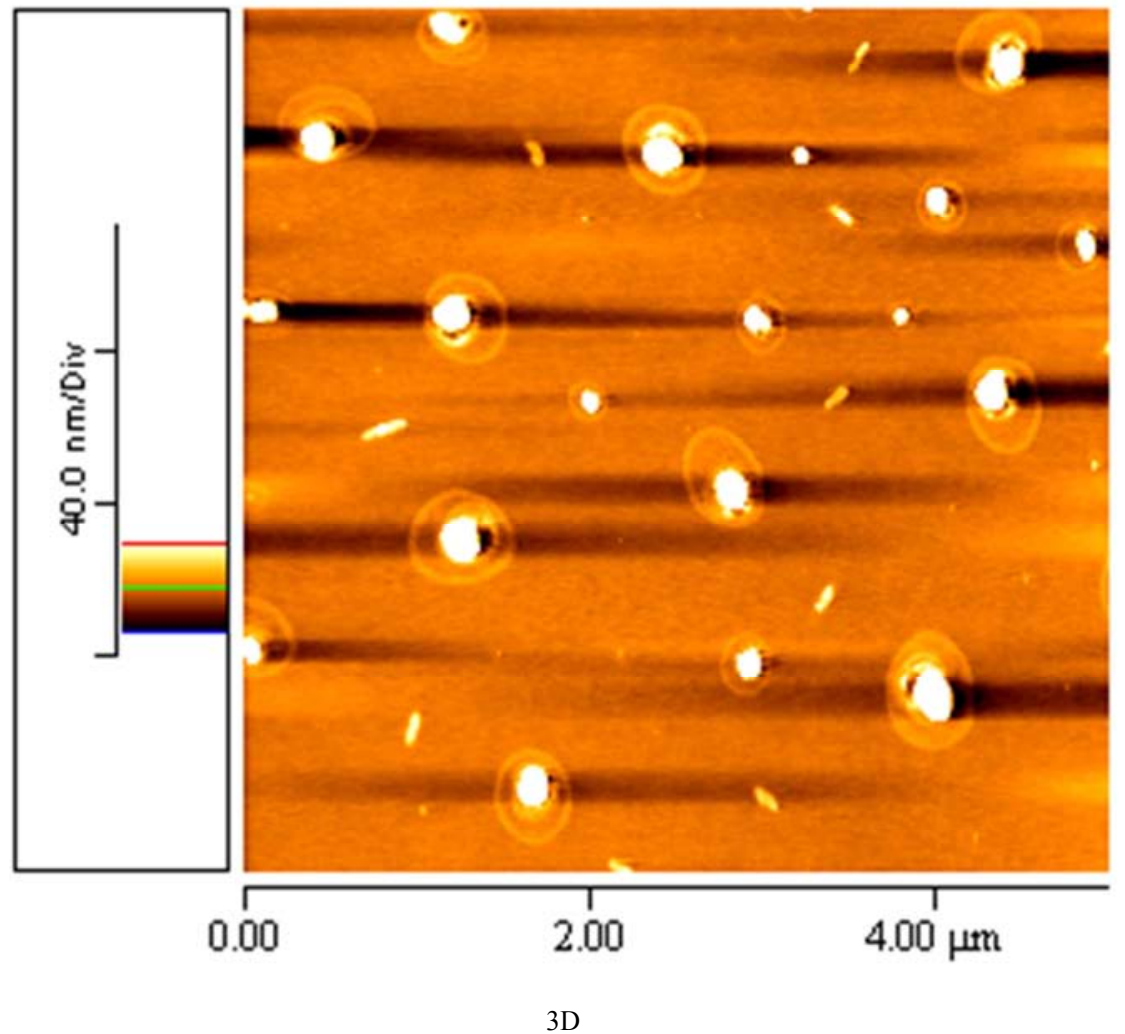

Figure 3. $A F M 2 D$ and $3 D$ morphological images of Dendrimer-folate conjugate. 


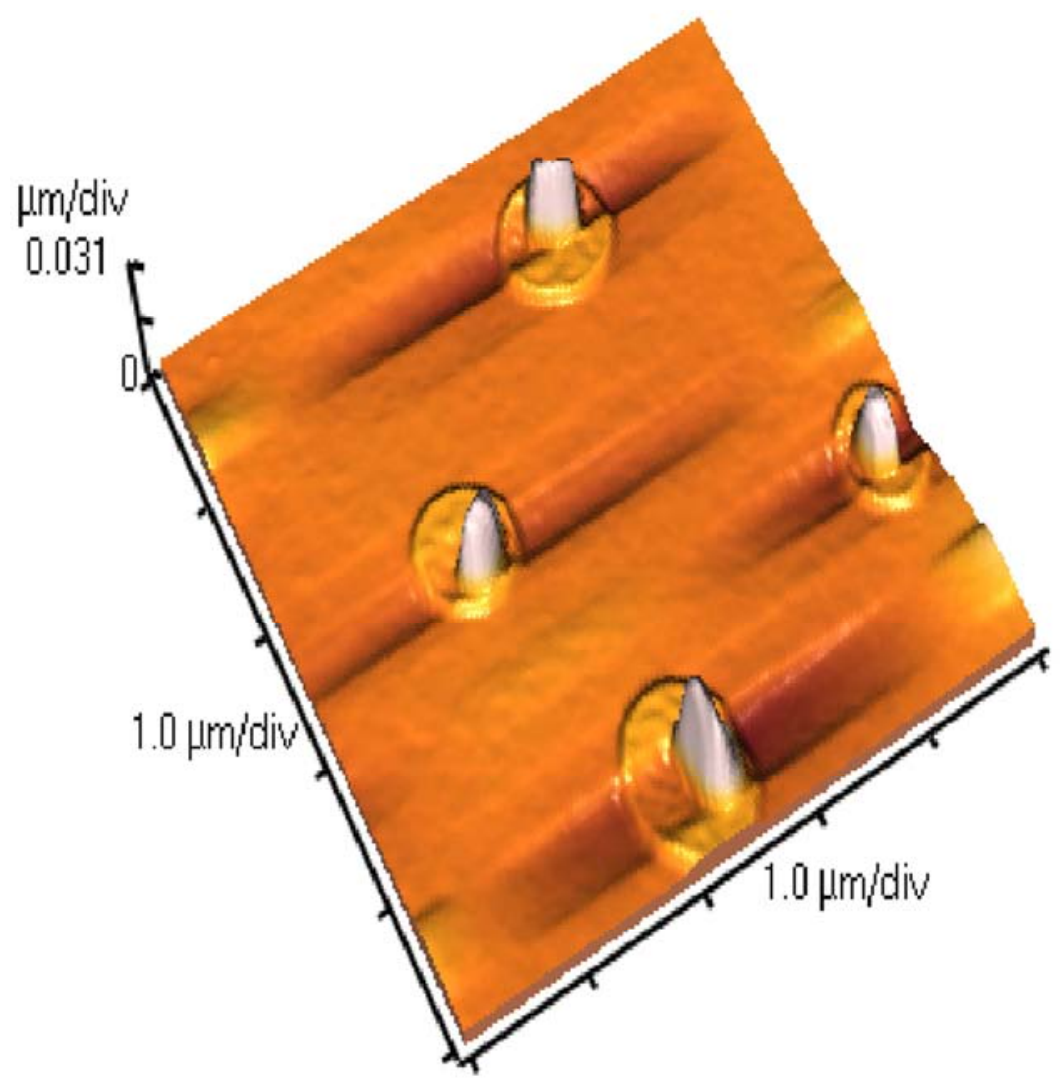

$2 \mathrm{D}$

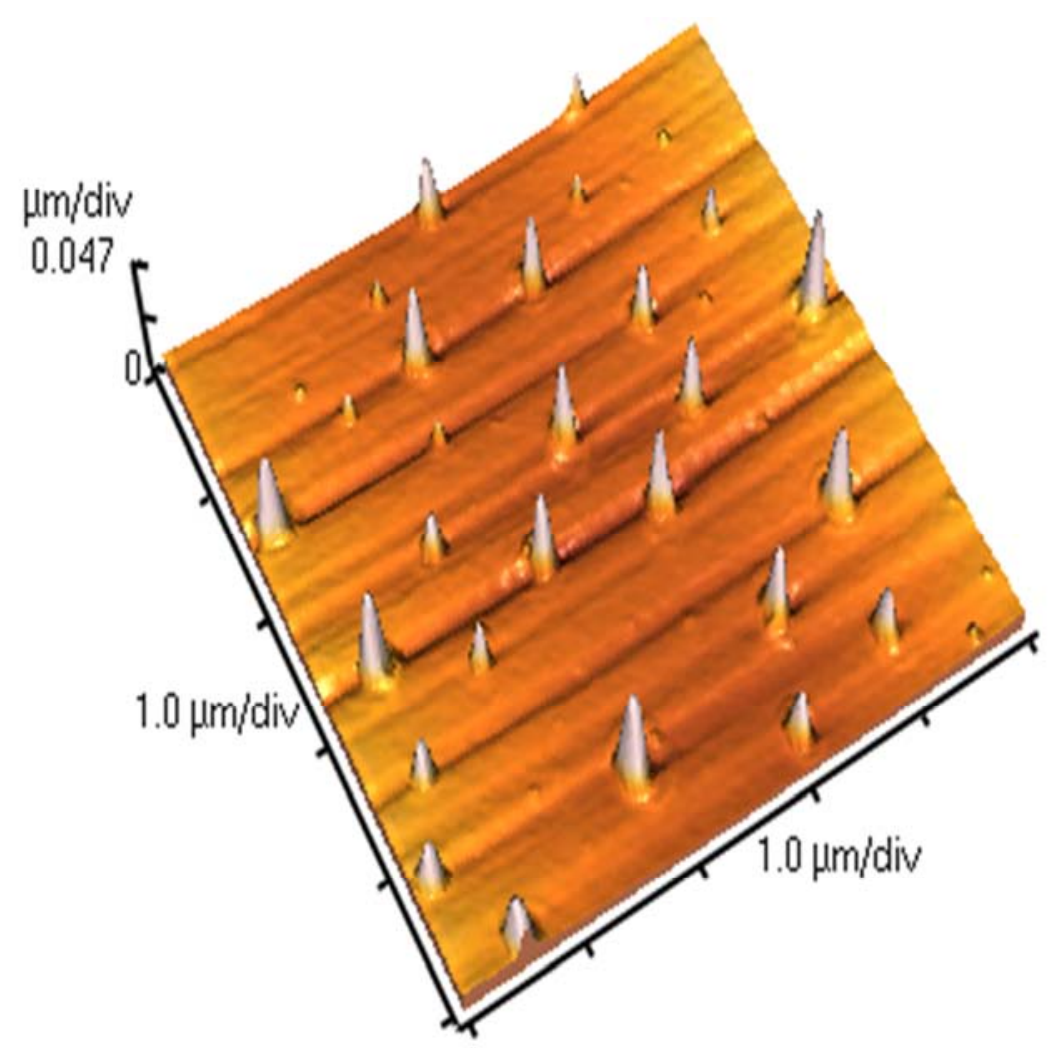

$3 \mathrm{D}$

Figure 4. AFM $2 D$ and $3 D$ morphological images of iron-complex-Nanoprobe. 


\subsection{In-Vitro Experiments}

\subsubsection{Cellular Uptake Analysis}

The figure 5 compares the cellular uptake of SPIONP loaded FA-Dendrimer conjugate with the reference drug Magnevist. The results show that SPIONP loaded FA-
Dendrimer conjugate penetrates better into the cells. Moreover, the SPIONP loaded FA-Dendrimer conjugate follows a dose dependent cellular uptake while Magnevist did not show such pattern and its uptake did not increase significantly with higher dose $(\mathrm{P}<0.05)$.

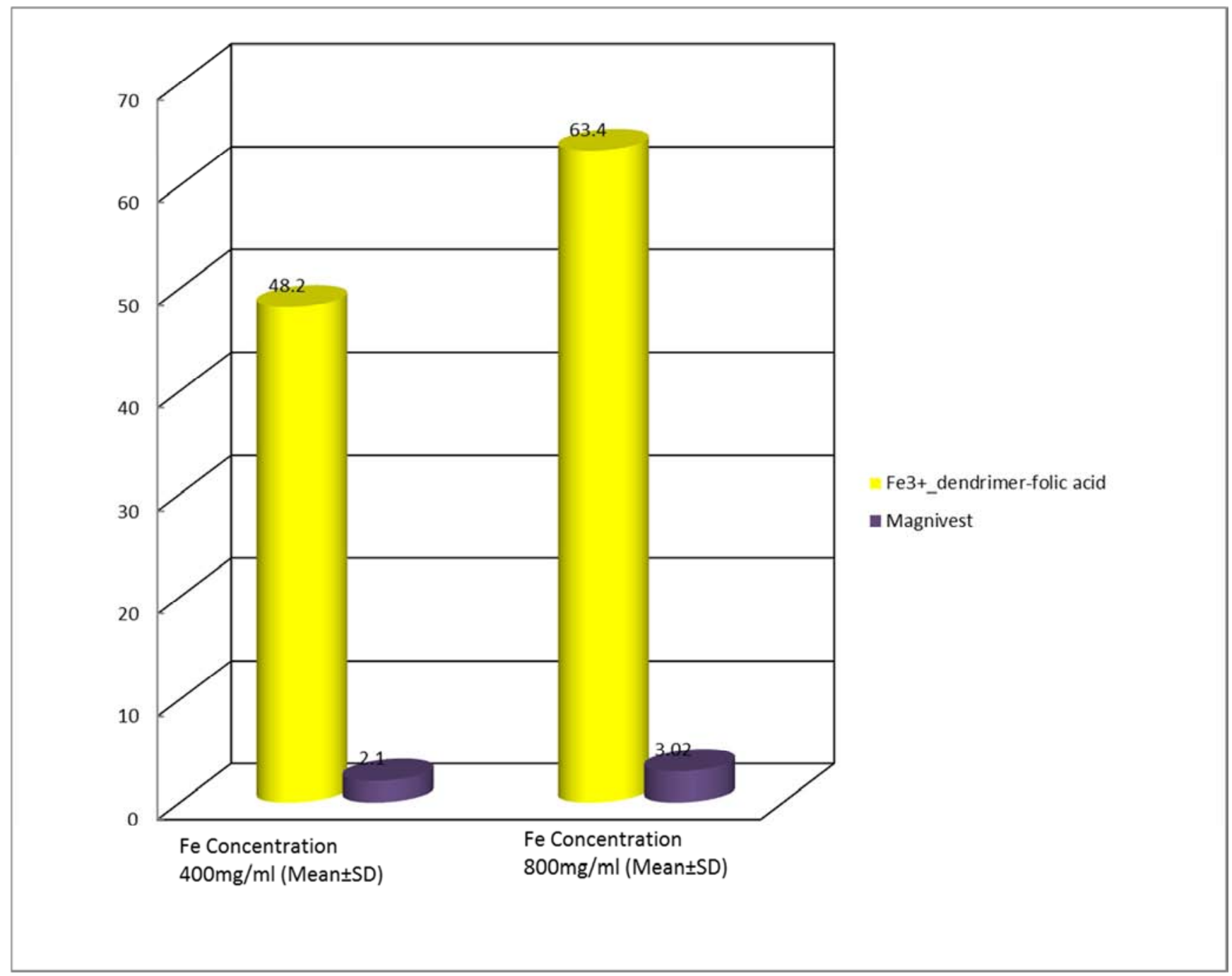

Figure 5. Illustration of nanoprobe promising liability to enter the cancerous cells with different doses comparing to standard drug magnevist.

\subsubsection{Cytotoxicity Assay}

Regarding the cytotoxicity assay results (Table 1) it was observed that the contrast agent did not reveal major cytotoxicity on the MCF-7 cancer cells and hence, it could be biocompatible.

Table 1. Cytotoxicity assay.

\begin{tabular}{|c|c|c|c|}
\hline Test group & Elisa OD at $450 \mathrm{~nm}$ & mean & viability \\
\hline Untreated cells $(1 \mu$ lit DMSO) & $1.25,1.42$ & 1.33 & $100 \%$ \\
\hline Drug Without $\mathrm{Fe}^{3+}(1 \mu \mathrm{g} / \mathrm{mL})$ & $0.29,0.28$ & 0.28 & $21 \%$ \\
\hline Drug Without $\mathrm{Fe}^{3+}(0.1 \mu \mathrm{g} / \mathrm{mL})$ & $1.20,1.31$ & 1.25 & $95 \%$ \\
\hline Drug Without $\mathrm{Fe}^{3+}(0.01 \mu \mathrm{g} / \mathrm{mL})$ & $1.34,1.28$ & 1.31 & $98 \%$ \\
\hline Drug Without $\mathrm{Fe}^{3+}(0.001 \mu \mathrm{g} / \mathrm{mL})$ & $1.37,1.43$ & 1.14 & $86 \%$ \\
\hline Drug With $\mathrm{Fe}^{3+}(1 \mu \mathrm{g} / \mathrm{mL})$ & $0.41,0.39$ & 0.4 & $30 \%$ \\
\hline Drug With $\mathrm{Fe}^{3+}(0.1 \mu \mathrm{g} / \mathrm{mL})$ & $1.36,1.22$ & 1.29 & $96 \%$ \\
\hline Drug With $\mathrm{Fe}^{3+}(0.01 \mu \mathrm{g} / \mathrm{mL})$ & $1.18,1.10$ & 1.14 & $85 \%$ \\
\hline Drug With $\mathrm{Fe}^{3+}(0.001 \mu \mathrm{g} / \mathrm{mL})$ & $1.20,0.99$ & 1.09 & $82 \%$ \\
\hline
\end{tabular}




\subsection{Relaxation Time Determination (in Vitro MR Imaging)}

Figures 6 show the results of the T2 relaxation time study. Different doses of the contrast agent are compared with water.

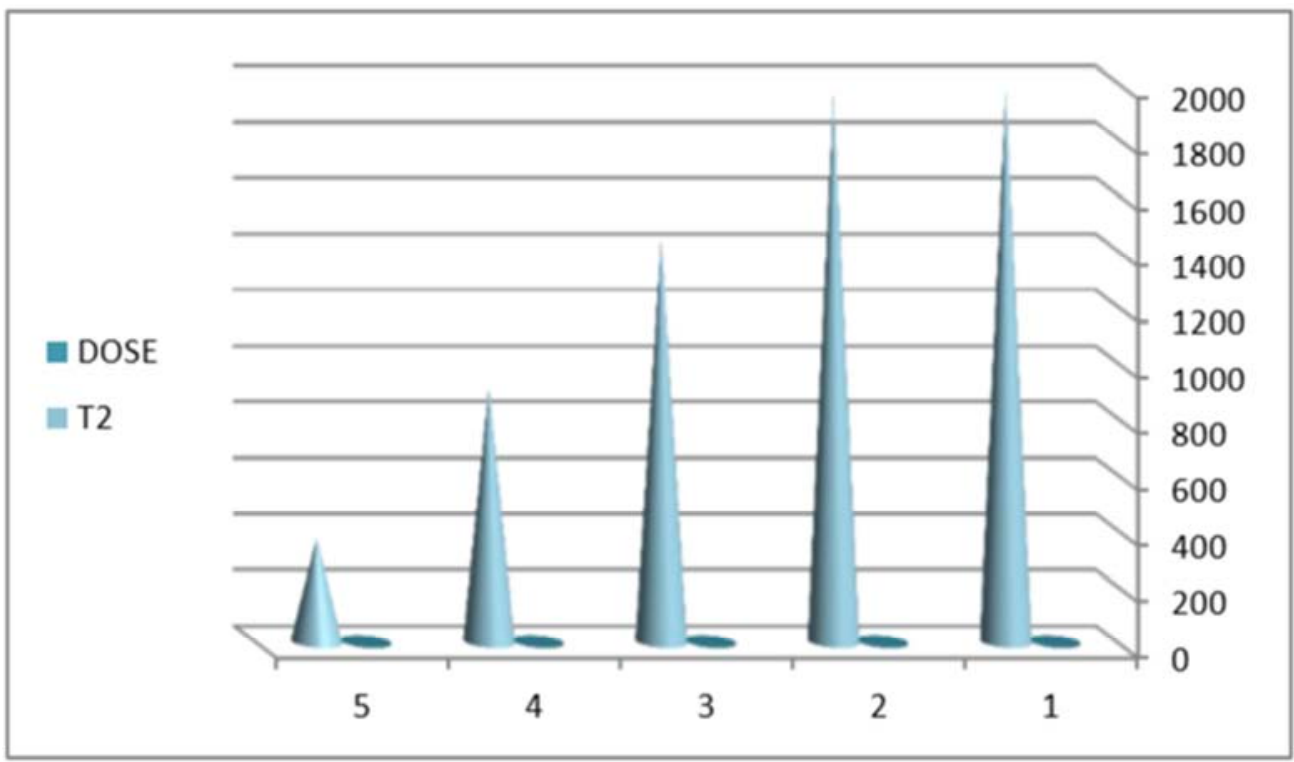

Figure 6. Demonstration of relaxivity of $T 2$ parameter regarding the synthesized nanoprobe.

\section{Conclusions}

The Functionalized G2 anionic straight globular dendrimer that is water dissolvable stage exchange operator, monodisperse, low harmful, exceedingly steady and fit for stacking a lot of atoms as a result of high porosity, was effectively connected to convey magnetite iron to the malignant cells while its biophysical and attractive properties were steady. Biocompatibility and biodegradability as essential issues in medication bearer choice has been tended to in the present PEG-citrate dendrimer biodegradable structure made out of endogenous biocompatible monomers promptly metabolized in vivo and in this manner, appropriate contender for clinical applications. Also, their water dissolvability due to the PEG base renders them the capacity to solubilize hydrophobic atoms. Consequently, the nanoparticles stay solvent regardless of stacking substantial measure of iron. In any case, the PEG structure demonstrates some anticancer impacts and could focus on the harmful tissue however in lower reviews as opposed to FA focusing on. The SPIONP stacked FA-Dendrimer conjugate gives striking soundness in water, re-suspend capacity in water, low irreversible accumulation and helpful stockpiling in lyophilized frame. Be that as it may, it ended up being proficient in focused conveyance, cell take-up and high imaging capacity while generally non-cytotoxic.

\section{Conflict of Interests}

The authors declared that they have not any conflict of interest.

\section{References}

[1] Na, H. B., I. C. Song, and T. Hyeon, Inorganic nanoparticles for MRI contrast agents. Advanced Materials, 2009. 21 (21): p. 2133-2148.

[2] Lodhia, J., et al., Development and use of iron oxide nanoparticles (Part 1): Synthesis of iron oxide nanoparticles for MRI. Biomedical imaging and intervention journal, 2010. 6 (2): p. e12.

[3] Wang, S. H., et al., Dendrimer-Functionalized Iron Oxide Nanoparticles for Specific Targeting and Imaging of Cancer Cells. Advanced Functional Materials, 2007. 17 (16): p. 30433050 .

[4] Peng, X.-H., et al., Targeted magnetic iron oxide nanoparticles for tumor imaging and therapy. International journal of nanomedicine, 2008. 3 (3): p. 311.

[5] Choi, H., et al., Iron oxide nanoparticles as magnetic resonance contrast agent for tumor imaging via folate receptor-targeted delivery 1. Academic radiology, 2004. 11 (9): p. 996-1004.

[6] Arsalani, N., H. Fattahi, and M. Nazarpoor, Synthesis and characterization of PVP-functionalized superparamagnetic $\mathrm{Fe}_{3} \mathrm{O}_{4}$ nanoparticles as an MRI contrast agent. Express Polym Lett, 2010.4 (6): p. 329-38.

[7] Tomalia, D., L. Reyna, and S. Svenson, Dendrimers as multipurpose nanodevices for oncology drug delivery and diagnostic imaging. Biochemical Society Transactions, 2007. 35 (1): p. 61.

[8] Landmark, K. J., et al., Synthesis, characterization, and in vitro testing of superparamagnetic iron oxide nanoparticles targeted using folic acid-conjugated dendrimers. ACS nano, 2008. 2 (4): p. 773-783. 
[9] Rosen, J. E., et al., Iron oxide nanoparticles for targeted cancer imaging and diagnostics. Nanomedicine: Nanotechnology, Biology and Medicine, 2012. 8 (3): p. 275290.

[10] Swanson, S. D., et al., Targeted gadolinium-loaded dendrimer nanoparticles for tumor-specific magnetic resonance contrast enhancement. International journal of nanomedicine, 2008. 3 (2): p. 201.
[11] Ardestani, M. S., et al., Nanosilver based anionic linear globular dendrimer with a special significant antiretroviral activity. Journal of Materials Science: Materials in Medicine, 2015. 26 (5): p. 1-8.

[12] Karimi, N., et al., Anionic Linear Globular Dendrimer-G2Ciprofloxacin Nano-Conjugate: Novel Agent against Wilson Disease Cell Model. Letters in Drug Design \& Discovery, 2014. 11 (7): p. 908-916. 